\title{
Evaluation of the Performance of Pt-MWCNTs Nanocomposites Electrodeposited on Titanium for Methanol Electro-oxidation
}

\author{
M.M. Momeni* \\ Department of Chemistry, Isfahan University of Technology, Isfahan 84156-83111, Iran
}

Received July 19, 2015; accepted October 01, 2015

\begin{abstract}
Pt nanoparticle-multi walled carbon nanotubes nanocomposites supported on titanium substrate (Pt-MWCNTs/Ti) were prepared by co-electrodeposition method. This composite catalyst was characterized by scanning electron microscopy (SEM), energy dispersive spectrum (EDS), and electrochemical methods. The SEM images reveal that nanostructures are distributed at the surface of the titanium plate. Electro-oxidation of methanol was investigated in acidic media on Pt-MWCNTs/Ti electrodes via cyclic voltammetric analysis in the mixed $0.1 \mathrm{M}$ methanol and $0.1 \mathrm{M} \mathrm{H} 2 \mathrm{SO} 4$ solutions. The Pt-MWCNTs/Ti catalyst has good electro-catalytic activity for methanol oxidation. This novel Pt-MWCNTs/Ti catalyst can be used repeatedly and exhibits stable electrocatalytic activity for the methanol oxidation.
\end{abstract}

Keywords: Platinum nanoparticles, Multi walled carbon nanotubes, Methanol, Titanium.

\section{Introduction}

Direct alcohol fuel cells (DAFCs) based on liquid fuels have attracted much attention as power sources for portable electronic devices and fuel cell vehicles, due to their much higher energy density than gaseous fuels such as hydrogen [14]. Studies aiming at developing efficient fuel cells have greatly contributed to the development of catalysts for the electro-oxidation of small organic molecules. Among these substances, methanol has been the most investigated due to the possibility of using it as a fuel in direct methanol fuel cells (DMFC).

Direct methanol fuel cells (DMFCs) are potential alternative energy sources for portable electronic devices, because of their high energy-conversion efficiency,

\footnotetext{
* Corresponding author. E-mail address: mm.momeni@cc.iut.ac.ir.
} 
low pollution emission, and safe fuel handling [5]. An effective catalyst is a key factor for the realization of DMFCs applications. It is largely accepted that $\mathrm{Pt}$ and Pt alloys are still indispensable and the most effective catalysts for the electrooxidation of methanol in DMFCs [6-8]. However, the increasing use of Pt and Pt alloys may raise the price of electro-catalyst and deplete a scarce resource. Thus, one of the grand challenges in DMFC development is how to reduce the use of precious Pt. One approach to cost reduction is to use Pt-based alloys, and another way is to efficiently utilize $\mathrm{Pt}$ by distributing limited $\mathrm{Pt}$ nanostructures on a suitable support [9-12]. Immobilization of Pt nanostructures in an active matrix may enhance the overall reactivity of catalytic metal centers. In the literature on optimum support for dispersed metal nanoparticles, attention shall be paid not only to systems stability and feasibility of fast charge propagation, but also to the existence of the activation of mutual metal-support interactions. In order to reduce the amount of noble metal loading and also enhance electro-catalytic activity of electrodes, there have been considerable efforts to increase dispersion of metal particles on different supports. Titanium is corrosion-resistant, has a high mechanical strength, a reasonable cost, wide electrochemical potential windows and good stability. Because of its excellent properties, titanium has been applied as a substrate in order to prepare novel and stable electro-catalysts including the well-known dimensionally stable anodes (DSA) [13-15]. Compared with the conventional structure of the anode, the titanium anode has many advantages, such as simplicity, easy production on a mass scale, low cost and flexibility in terms of shape [16]. In recent years, carbon nanotubes have received increasing attention, regarding the preparation of modified electrodes, due to their unique structures and extraordinary properties, such as a huge surface area, strong stability and efficient catalytic activity which can promote charge transfer reaction. At the present, carbon nanotubes are widely used in the electrochemical field [17-19]. To the best of our knowledge, electro-oxidation of methanol on titanium-coated with platinum nanoparticle-multi walled carbon nanotubes has not been reported in the literature. In the present work, we have prepared an electro-catalyst based on the co-deposition of platinum nanoparticle-multi walled carbon nanotubes on titanium plate and have studied their electrochemical activity for methanol electro-oxidation using cyclic voltammetry $(\mathrm{CV})$.

\section{Experimental}

\section{Chemicals, Solutions and Electrochemical measurement}

Methanol (Merck, 99\% purity) and H2SO4 (Merck, 99\% purity) were used as received. Hexachloroplatinic acid (98\%) was purchased from Merck. All other chemicals were of analytical grade and used without further purification. All electrochemical experiments were carried out at room temperature. Distilled water was used throughout. The electrochemical experiments were performed in a three-electrode cell arrangement. A platinum sheet was used as counter electrode, while all potentials were measured with respect to a commercial saturated calomel reference electrode (SCE). Electrochemical experiments were carried out by the IviumStat electrochemical analyzer (IVIUM Technology, The Netherlands). 


\section{Preparation of Pt-MWCNTs/Ti and Pt/Ti electrodes}

Titanium discs were cut from a titanium plate and mounted using polyester resin. Titanium electrodes were first mechanically polished and then chemically etched by immersion in a mixture of $\mathrm{HF}: \mathrm{HNO}_{3}$ 1:3 solution for $1 \mathrm{~min}$. Prior to electrodeposition, titanium samples were degreased by sonicating in acetone and ethanol followed by rinsing with distilled water.

Untreated MWNTs were ultrasonically treated with a 3:1 mixture of concentrated $\mathrm{H}_{2} \mathrm{SO}_{4}$ and $\mathrm{HNO}_{3}$ for $4 \mathrm{~h}$, which produced carboxylic acid groups at the defect sites and thus improved the solubility of the c-MWNTs in acidic solution, and then washed with distilled water several times until the $\mathrm{pH}$ of the solution became neutral ( $\mathrm{pH}$ 7). The carboxylic MWNTs were dried and stored until use. Afterwards, $10 \mathrm{mg}$ carboxylic MWNTs were dispersed in $100 \mathrm{~mL}$ of $0.5 \mathrm{M}$ $\mathrm{H}_{2} \mathrm{SO}_{4}$ solution containing $1 \mathrm{mM} \mathrm{H}_{2} \mathrm{PtCl}_{6}$ by ultrasonics over $1 \mathrm{~h}$. The platinum nanoparticle-multi walled carbon nanotubes were electrochemically deposited at the surface of titanium substrate from this bath. The deposition conditions were a current density of $10 \mathrm{~mA} \mathrm{~cm}{ }^{-2}$ for $5 \mathrm{~min}$ and the temperature was maintained at $45^{\circ} \mathrm{C}$. For preparation of $\mathrm{Pt} / \mathrm{Ti}$ electrodes, the $\mathrm{Pt}$ was electrochemically deposited at the surface of titanium substrate from $1 \mathrm{mM} \mathrm{H}_{2} \mathrm{PtCl}_{6}$ in aqueous $0.5 \mathrm{M} \mathrm{H}_{2} \mathrm{SO}_{4}$ solution as the supporting electrolyte. Here again, the deposition conditions were a current density of $10 \mathrm{~mA} \mathrm{~cm}^{-2}$ for $5 \mathrm{~min}$ and the temperature was maintained at $45{ }^{\circ} \mathrm{C}$.

In order to determine how much Pt (mass) was present on titanium substrates, the final platinum loading, as measured by dissolution of the deposit followed by ICP analysis was about $0.6 \mathrm{mg} \mathrm{cm}^{-2}$ (for Pt-MWCNTs/Ti) and $1.1 \mathrm{mg} \mathrm{cm}^{-2}$ (for $\mathrm{Pt} / \mathrm{Ti}$ ) electrodes.

\section{Results and discussion}

Morphology of Pt-MWCNTs/Ti electrode

Fig. 1 illustrates the SEM images of Pt-MWCNTs films deposited on the titanium plate. It can be seen that platinum nanoparticles and MWCNTs are distributed in an almost homogeneous manner at the surface of the titanium plate. The EDX confirms the presence of Pt on the modified electrode.

\section{Characterization of the Pt-MWCNTs/Ti electrode surface}

To determine whether the electro-deposition procedure has resulted in the removal of the oxide layer, thereby ensuring good electrical contact between the deposited composite film and the underlying substrates, the Pt-MWCNTs/Ti were tested as electrodes using one electron redox couple. Fig. 2 (A and B) shows the voltammetric curves for the reduction of $\mathrm{K}_{3} \mathrm{Fe}(\mathrm{CN})_{6}$ on flat platinum, Pt-MWCNTs/Ti and bare titanium electrodes. The voltammogram for the PtMWCNTs/Ti electrodes shows the expected reversible behavior for the reduction on a bulk platinum electrode (Fig. 2A). In comparison, the CVs obtained with titanium electrode show increased peak separation and peak widths (Fig. 2B). This is probably attributable to a passivating surface film, most likely the oxide 
layer present on the surface of the titanium electrode. The lack of such resistances and over-potentials observed on repeated redox cycling of PtMWCNTs/Ti electrodes indicates that there is no significant resistive film between the underlying titanium and the deposited composite film. It suggests that the adhesion and electrical contact property of the deposited composite film with titanium is quite satisfactory [20].
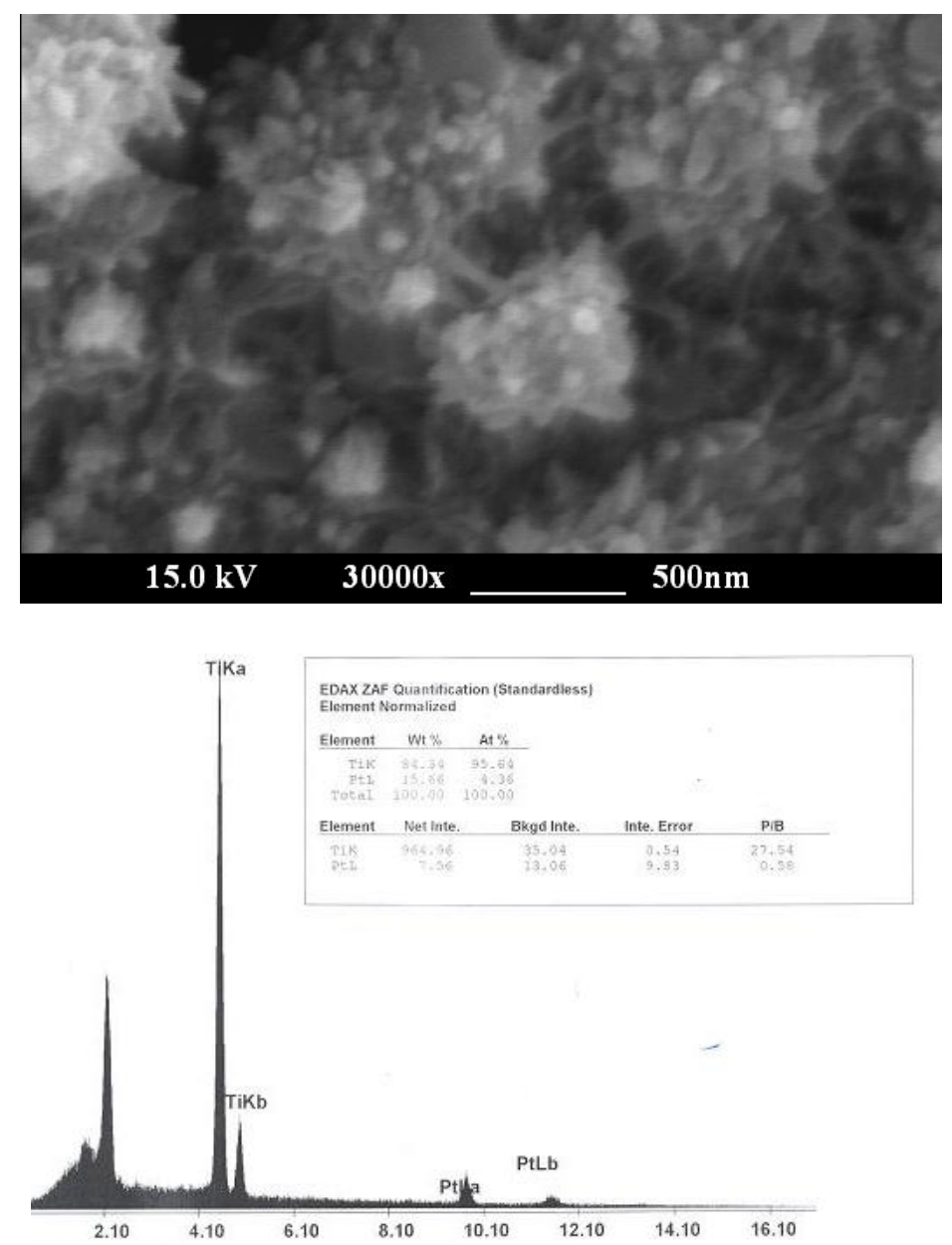

Figure 1. Scanning electron microscopic (SEM) image of Pt-MWCNTs films deposited on the titanium and EDX of Pt-MWCNTs/Ti electrode.

To understand the electrochemical activity of the Pt-MWCNTs/Ti, the cyclic voltammetric responses of the $\mathrm{Pt}-\mathrm{MWCNTs} / \mathrm{Ti}, \mathrm{Pt} / \mathrm{Ti}$ and bare titanium electrodes were recorded at a scan rate of $100 \mathrm{mV} \mathrm{s}^{-1}$. Fig. 3 shows the cyclic voltammograms of the Pt-MWCNTs/Ti, bare titanium and Pt/Ti (inset) in $0.1 \mathrm{M}$ $\mathrm{H}_{2} \mathrm{SO}_{4}$ solution. Although the typical Pt-peaks for the hydrogen deposition (a), the oxidation of hydrogen ( $\left.a^{\prime}\right)$, formation of platinum oxide (b), and its reduction (b') are present on the Pt-MWCNTs/Ti, they become ill-shaped compared to $\mathrm{Pt} / \mathrm{Ti}$ (inset) [21-23]. Also, curve 3 shows the cyclic voltammetric of bare titanium substrate in $0.1 \mathrm{M} \mathrm{H}_{2} \mathrm{SO}_{4}$ solution. No adsorption/desorption peaks of hydrogen appeared at the bare titanium. 

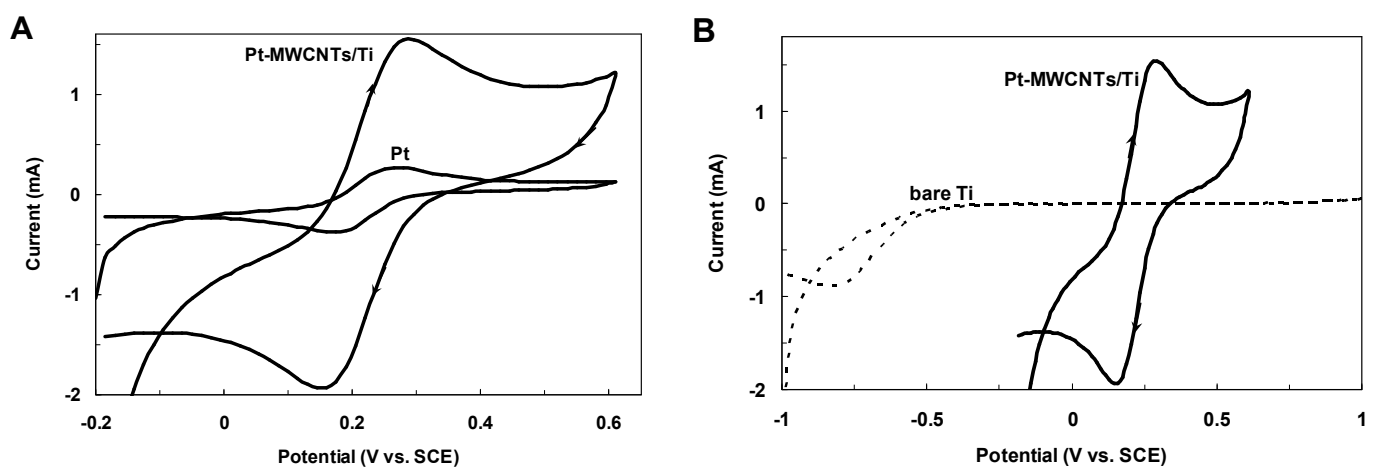

Figure 2. (A) Cyclic voltammograms for Pt-MWCNTs/Ti $\left(1 \times 1 \mathrm{~cm}^{2}\right)$ and smooth platinum $\left(1 \times 1 \mathrm{~cm}^{2}\right)$ electrodes recorded at $100 \mathrm{mV} \mathrm{s}^{-1}$ in a solution containing $10 \mathrm{mM}$ $\mathrm{K}_{3}\left[\mathrm{Fe}(\mathrm{CN})_{6}\right]+1 \mathrm{M} \mathrm{KCl}$ at $25{ }^{\circ} \mathrm{C}$ with a scan rate of $100 \mathrm{mV} \mathrm{s}^{-1}$. (B) Cyclic voltammograms for bare titanium electrode $\left(1 \times 1 \mathrm{~cm}^{2}\right)$ and Pt-MWCNTs/Ti $\left(1 \times 1 \mathrm{~cm}^{2}\right)$ electrode recorded at $100 \mathrm{mV} \mathrm{s}^{-1}$ in a solution containing $10 \mathrm{mM} \mathrm{K}_{3}\left[\mathrm{Fe}(\mathrm{CN})_{6}\right]+1 \mathrm{M}$ $\mathrm{KCl}$ at $25^{\circ} \mathrm{C}$ with a scan rate of $100 \mathrm{mV} \mathrm{s}^{-1}$.

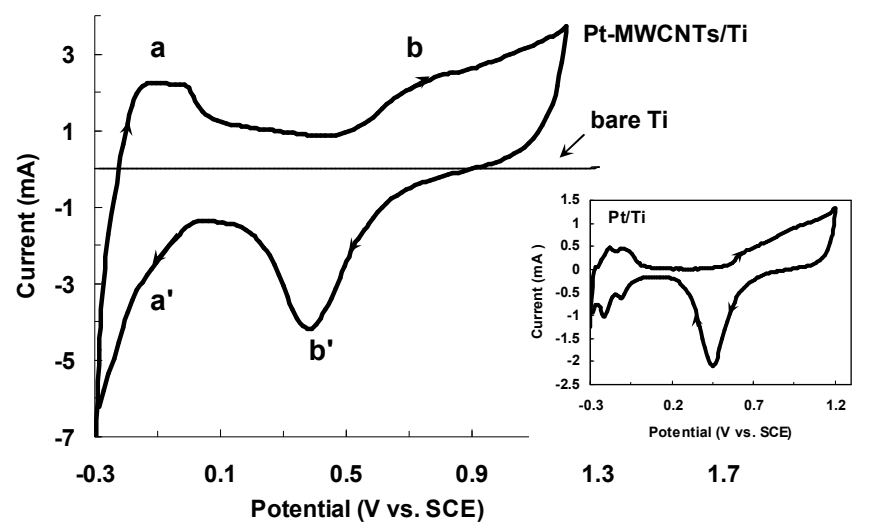

Figure 3. Cyclic voltammograms of Pt-MWCNTs/Ti and bare titanium electrodes in 0.1 $\mathrm{M} \mathrm{H}_{2} \mathrm{SO}_{4}$ at a scan rate of $100 \mathrm{mV} \mathrm{s}^{-1}$. The inset is $\mathrm{CV}$ of $\mathrm{Pt} / \mathrm{Ti}$ in the same conditions.

\section{Oxidation of methanol on the Pt-MWCNTs/Ti catalyst}

In order to compare the Pt-MWCNTs/Ti electrode with Pt/Ti electrode, the cyclic voltammetry method was used to estimate the electro-catalytic behavior of the electrodes. Fig. 4 shows the comparison of oxidation of methanol on Pt/Ti and the Pt-MWCNTs/Ti electrodes. It can be seen from Fig. 4 that the cyclic voltammogram of Pt-MWCNTs/Ti electrode (curve II) shows the usual characteristics of $\mathrm{Pt} / \mathrm{Ti}$ electrode (curve I), except that for both forward and reverse scan directions the oxidation currents of methanol on the Pt-MWCNTs/Ti electrode are significantly higher than on $\mathrm{Pt} / \mathrm{Ti}$ electrode. Fig. 4, inset A, shows the cyclic voltammograms of $\mathrm{Pt} / \mathrm{Ti}$ electrode in $0.1 \mathrm{M} \mathrm{H}_{2} \mathrm{SO}_{4}$ aqueous solution at a scan rate of $100 \mathrm{mV} \mathrm{s}^{-1}$ without methanol (dash line) and in the presence of 0.1 $\mathrm{M}$ methanol (solid line). Cyclic voltammetry data were recorded for PtMWCNTs/Ti electrode in $0.1 \mathrm{M} \mathrm{H}_{2} \mathrm{SO}_{4}$ aqueous solution at a scan rate of 100 $\mathrm{mV} \mathrm{s}^{-1}$ without methanol (dash line) and in the presence of $0.1 \mathrm{M}$ methanol (solid line), as shown in Fig. 4 (inset B). It can be seen from the cyclic voltammetry of methanol oxidation on the Pt-MWCNTs/Ti electrode that the reaction 
commences in the hydrogen region and proceeds slowly in the positive direction, and then reaches a plateau at about $-0.10 \mathrm{~V}$. At potentials with more than $0.25 \mathrm{~V}$, the reaction becomes accelerated and maximum rate at ca. $0.83 \mathrm{~V}$ occurs. At potentials above $0.83 \mathrm{~V}$ the oxidation of platinum and formation of platinum oxides cause a decrease in the amount of active sites available on the electrode surface which subsequently result in a decrease of peak current. Upon reversing the potential sweep, a very steep increase of the reaction rate at ca. $0.65 \mathrm{~V}$ develops and a maximum current is observed at ca. $0.55 \mathrm{~V}$. In the backward scan, the reduction of platinum oxides to platinum and production of active sites take place, so re-oxidation of methanol and/or methanol residues occurs on clean platinum surface and backward peak at $0.55 \mathrm{~V}$ appears [24, 25].
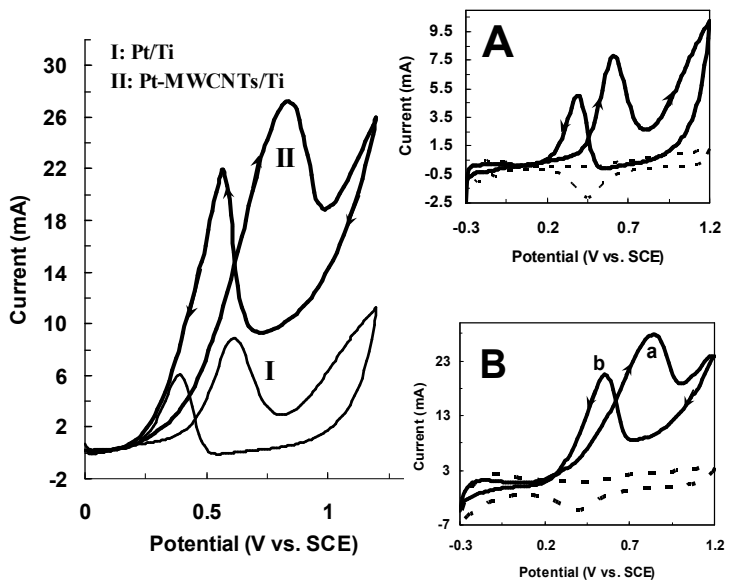

Figure 4. Cyclic voltammograms for (I) Pt/Ti and (II) Pt-MWCNTs/Ti electrodes in 0.1 $\mathrm{M} \mathrm{H}_{2} \mathrm{SO}_{4}+0.1 \mathrm{M}$ methanol aqueous solution at $25^{\circ} \mathrm{C}$ with scan rate of $100 \mathrm{mVs}^{-1}$. (A) Cyclic voltammogram for $\mathrm{Pt} / \mathrm{Ti}$ electrode and (B) cyclic voltammograms for PtMWCNTs/Ti in $0.1 \mathrm{M} \mathrm{H}_{2} \mathrm{SO}_{4}$ without (dash line) and with (solid line) $0.1 \mathrm{M}$ methanol.

Electro-oxidation of methanol at platinum-based electrodes has been studied extensively. Results from infra-red spectroscopy show that methanol oxidation on platinum at low potentials lead to the formation of linearly bonded $\mathrm{CO}$ species. This species, which is strongly adsorbed on the platinum, acts as a catalyst poison. The surface reaction between this adsorbed $\mathrm{CO}$ species and adsorbed $\mathrm{OH}$ species, from water decomposition, causes the formation of carbon dioxide (final product of methanol oxidation) [25, 26]. According to the literature, it is well known that methanol oxidation process consists of the following steps that result in the formation of carboxyl intermediates and strongly adsorbed $\mathrm{CO}$ species [27-29]:

$$
\begin{aligned}
& \left(\mathrm{CH}_{3} \mathrm{OH}\right)_{\text {solution }} \rightarrow \mathrm{Pt}-\left(\mathrm{CH}_{3} \mathrm{OH}\right)_{\mathrm{ads}} \\
& \mathrm{Pt}-\left(\mathrm{CH}_{3} \mathrm{OH}\right)_{\mathrm{ads}} \rightarrow \mathrm{Pt}-\left(\mathrm{CH}_{3} \mathrm{O}\right)_{\mathrm{ads}}+\mathrm{H}^{+}+\mathrm{e}^{-} \\
& \mathrm{Pt}-\left(\mathrm{CH}_{3} \mathrm{O}\right)_{\mathrm{ads}} \rightarrow \mathrm{Pt}-\left(\mathrm{CH}_{2} \mathrm{O}\right)_{\mathrm{ads}}+\mathrm{H}^{+}+\mathrm{e}^{-} \\
& \mathrm{Pt}-\left(\mathrm{CH}_{2} \mathrm{O}\right)_{\mathrm{ads}} \rightarrow \mathrm{Pt}-(\mathrm{CHO})_{\mathrm{ads}}+\mathrm{H}^{+}+\mathrm{e}^{-} \\
& \mathrm{Pt}-(\mathrm{CHO})_{\mathrm{ads}} \rightarrow \mathrm{Pt}-(\mathrm{CO})_{\mathrm{ads}}+\mathrm{H}^{+}+\mathrm{e}^{-}
\end{aligned}
$$

Reactions (1)-(5) can be denoted by a total dissociative adsorption reaction: $\mathrm{Pt}-\left(\mathrm{CH}_{3} \mathrm{OH}\right)_{\text {solution }} \rightarrow \mathrm{Pt}-(\mathrm{CO})_{\mathrm{ads}}+4 \mathrm{H}^{+}+4 \mathrm{e}^{-}$ 
The complete methanol oxidation (reaction 7) can occur and cause the sharp increase in current of methanol oxidation peak:

$\mathrm{Pt}-(\mathrm{CO})_{\mathrm{ads}}+\mathrm{H}_{2} \mathrm{O} \rightarrow \mathrm{Pt}+\mathrm{CO}_{2}+2 \mathrm{H}^{+}+2 \mathrm{e}^{-}$

In order to investigate the kinetic characterization of methanol oxidation on the Pt-MWCNTs/Ti electrode, we have looked into the effect of the scan rate on the behavior of methanol oxidation. CVs of methanol oxidation on Pt-MWCNTs/Ti electrode at different scan rates were shown in Fig. 5. The result clearly reveals that the peak current associated to the methanol electro-oxidation increases linearly with the scan rate in the range $30-150 \mathrm{mV} \mathrm{s}^{-1}$. In principle, peak currents are proportional to the scan rate $(v)$ for an adsorption process and the square root scan rate $\left(v^{1 / 2}\right)$ for a diffusion process [30]. In inset $A$ curve a, peak currents were plotted as a function of the square root scan rate $\left(v^{1 / 2}\right)$. As it can be seen, the current value of main anodic peak $\left(\mathrm{I}_{\mathrm{pf}}\right)$ is liner vs. $v^{1 / 2}$. This behavior indicates that the electro-catalytic process under study is controlled by diffusion [31]. The dependence of methanol oxidation peak potential $\left(\mathrm{E}_{\mathrm{pa}}\right)$ on the scan rate indicates an irreversible charge-transport process (inset B) [30]. The potential of reoxidation peak $\left(\mathrm{E}_{\mathrm{pb}}\right)$ shifts negatively with the scan rate, because, most probably in high scan rates, the stability of platinum oxides increases, thus, their reduction in the backward scan requires more negative potentials [29].

In order to reveal the correlation between methanol oxidation and platinum oxide species, we have studied the effect of the upper limit potentials (EU) in the cyclic potential scanning on the methanol oxidation. The reason for that, as reported in the literature, is that the different ranges of potential, over which the formation and dissolution of surface oxides occur on the smooth platinum or on the Ptbased electrodes, form a striking feature of the electrochemical behaviors of these electrodes [32]. It is also reflected in a kinetic irreversibility of most electro-catalytic oxidation, even in the reduction reactions that proceed on these electrodes [33].

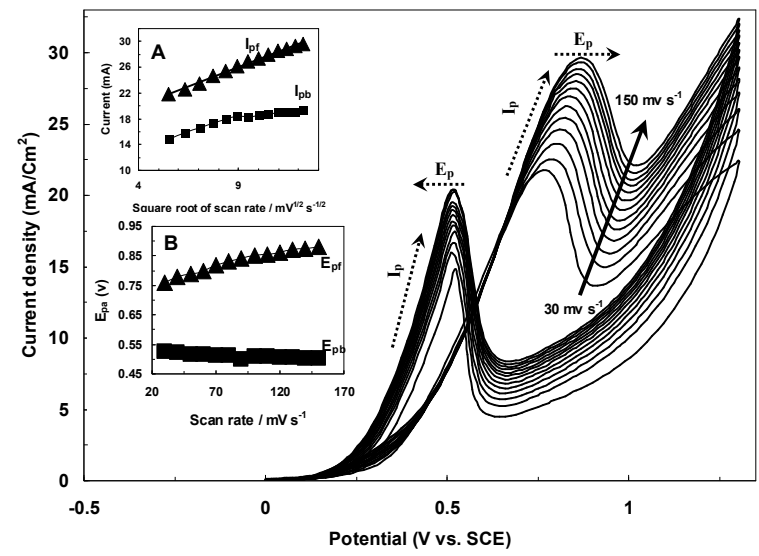

Figure 5. Cyclic voltammograms of Pt-MWCNTs/Ti electrodes in $0.1 \mathrm{M} \mathrm{H}_{2} \mathrm{SO}_{4}$ containing $0.1 \mathrm{M}$ methanol obtained at different scan rates (1-13), 30, 40, 50, 60, 70, 80, $90,100,110,120,130,140$ and $150 \mathrm{mV} \mathrm{s}^{-1}$. Inset A: variations of peak currents with square root of scan rate. Inset B: variations of peak potentials with scan rate. 
Fig. 6 shows the CVs of methanol oxidation on the Pt-MWCNTs/Ti electrodes for $\mathrm{EU}$ of $1.05-1.40 \mathrm{~V}$. As seen in figure 6, by increasing the final positive potential limit, the anodic current density of methanol oxidation in the positive going potential sweep (PGPS) remains unchanged, but the oxidation current density in the negative going potential sweep (NGPS) is decreased (Fig. 6B). According to reports in the literature, the re-oxidation peak for methanol is related to the oxidation of methanol and/or methanol residues $(\mathrm{Pt}-\mathrm{CO})$ in the backward scan. The reaction for the re-oxidation peak is assumed as follows [24]:

$\mathrm{Pt}-(\mathrm{OH})_{\mathrm{ads}}+\mathrm{Pt}-(\mathrm{CO})_{\mathrm{ads}} \rightarrow \mathrm{CO}_{2}+\mathrm{H}^{+}+2 \mathrm{Pt}+\mathrm{e}^{-}$

In the lower limit potential, Pt oxides with a high valence do not develop greatly, so, the effect of the Pt oxides with a high valence on the methanol oxidation in the NGPS is relatively small. It can also be seen that the potential of the methanol oxidation peak remains invariable in PGPS, while the potential of the methanol oxidation peak shifts positively in NGPS (Fig. 6C). On the other hand, the peak current density in NGPS decreased, as EU increased. Indeed, by increasing the final positive potentials, the conversion of $\mathrm{Pt}$ to $\mathrm{PtO}$ is accelerated, causing a decrease of the oxidation current density in NGPS, which further demonstrates that methanol can only be oxidized on a clean metallic platinum nanoparticles surface [20].
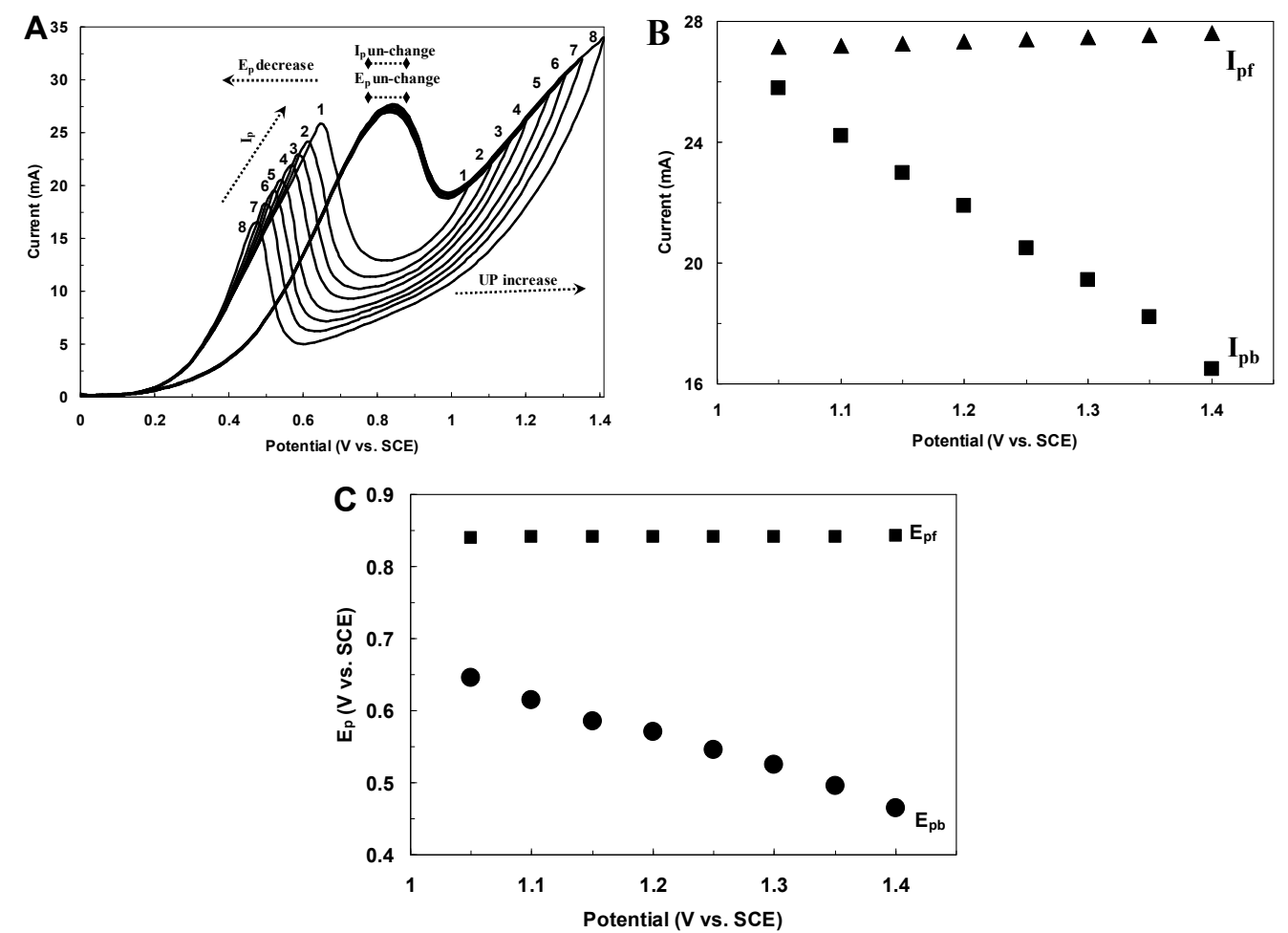

Figure 6. (A) Effect of upper limit of potential scanning region on the electro-oxidation of $0.1 \mathrm{M}$ methanol on the Pt-MWCNTs/Ti electrodes in $0.1 \mathrm{M} \mathrm{H}_{2} \mathrm{SO}_{4}$ from (1) 0.0-1.05 $\mathrm{V}$ to (8) $0.0-1.40 \mathrm{~V}$ with a scan rate of $100 \mathrm{mV} \mathrm{s}^{-1}$. (B) Plot of anodic peak current in forward $\left(I_{\mathrm{pf}}\right)$ and in backward scan $\left(I_{\mathrm{pb}}\right)$. (C) Variation of anodic peak potential in forward $\left(E_{\mathrm{pf}}\right)$ and in backward scan $\left(E_{\mathrm{pb}}\right)$. 
In order to evaluate the capacity of Pt-MWCNTs/Ti for electro-oxidation of methanol, the effect of methanol concentration on the corresponding main anodic peak currents was investigated by cyclic voltammetry. According to experimental data the peak current of methanol was increased by methanol concentration, and reached a nearly constant value for concentrations higher than 1.5 $\mathrm{M}$ methanol. We assume this effect was caused by saturation of active sites at the surface of the electro-catalyst.

The effect of $\mathrm{H}_{2} \mathrm{SO}_{4}$ concentration on the peak current related to the electrooxidation of methanol at Pt-MWCNTs/Ti electrode has been investigated by cyclic voltammetry. The variation of the peak current obtained for methanol oxidation (main anodic peak) was plotted against $\mathrm{H}_{2} \mathrm{SO}_{4}$ concentration. The peak current of main anodic peak oxidation increases with the increase of $\mathrm{H}_{2} \mathrm{SO}_{4}$ concentration to $0.1 \mathrm{M}$, and then it remains constant for the optimum $\mathrm{H}_{2} \mathrm{SO}_{4}$ concentration range of $0.10-0.20 \mathrm{M}$. Further increase in $\mathrm{H}_{2} \mathrm{SO}_{4}$ concentration depressed the anodic peak current. It can be said that in high concentrations of $\mathrm{H}_{2} \mathrm{SO}_{4}$, the dissociation of acid decreases, causing the reduction of the solution conductivity. Also, the reducing effect of a high level $\mathrm{H}_{2} \mathrm{SO}_{4}$ concentration on peak currents may be addressed according to the Chatelier's principle, i.e. the thermodynamic tendency for oxidation of main anodic peak was reduced by $\mathrm{H}_{2} \mathrm{SO}_{4}$ concentration $[23,34]$, because, as it can be seen in reactions from (1)-(7), hydrogen ion was produced in the right sides. Therefore, as the concentration of hydrogen ion increases via increasing $\mathrm{H}_{2} \mathrm{SO}_{4}$ concentration, the reaction's progress will be reduced. On the other hand, according to the Chatelier's principle, if we are to add a species to the overall reaction, the reaction will favor the side opposing the addition of the species.

The long-term stability of the electro-catalyst is important from the viewpoint of the practical application. In order to evaluate the stability of the electro-catalytic activity of the Pt-MWCNTs/Ti electrode toward methanol electro-oxidation and also poisoning-resistance of the electro-catalyst, chronoamperometric measurements were performed. The obtained results on $\mathrm{Pt} / \mathrm{Ti}$ and $\mathrm{Pt}-$ MWCNTs/Ti electrodes in $0.1 \mathrm{M}$ methanol $+0.1 \mathrm{M} \mathrm{H}_{2} \mathrm{SO}_{4}$ solution were shown in Fig. 7. As it can be seen in Fig. 7A, in both curves, the currents dropped rapidly at first, and then became relatively stable, due to the fast poisoning of the platinum surface by adsorbed intermediates. Also, the decay of the oxidation current density on Pt-MWCNTs/Ti is much slower than that on Pt/Ti electrodes. This indicates that the Pt-MWCNTs/Ti electrodes have an acceptable stability in the electro-oxidation of methanol. On the other hand, the oxidation current on the Pt-MWCNTs/Ti electrodes is larger than that on Pt/Ti electrodes at the end of the experiment. This indicates that the Pt-MWCNTs/Ti electrode is a good poisoning-resistance electro-catalyst for methanol oxidation.

The continuous cycling in $\mathrm{CV}$ method can indicate that the present electrocatalyst has low stability in long-term using. The effect of continuous cycling and long-term stability of Pt-MWCNTs/Ti electrode was examined in $0.1 \mathrm{M} \mathrm{H}_{2} \mathrm{SO}_{4}$ solution containing $0.1 \mathrm{M}$ methanol (Fig. 7B). It can be observed that the anodic current remains constant with an increase in the scan number at the initial stage 
and then starts to decrease after 35 scans. The peak current of the $250^{\text {th }}$ scan is about $94 \%$ of that of the first scan. In general, the loss of catalytic activity after successive number of scans may result from the consumption of methanol during the CV scan. That may also be due to poisoning and the structural change of the Pt nanoparticles as a result of the perturbation of potentials during the scanning in aqueous solutions, especially in the presence of the organic compound.

After long-term stability experiments, the Pt-MWCNTs/Ti electrode was stored in water for a week; then methanol oxidation was carried out again by $\mathrm{CV}$, and excellent catalytic activity towards methanol oxidation was still observed. This indicates that Pt-MWCNTs/Ti electrodes have good long term stability and storage properties.
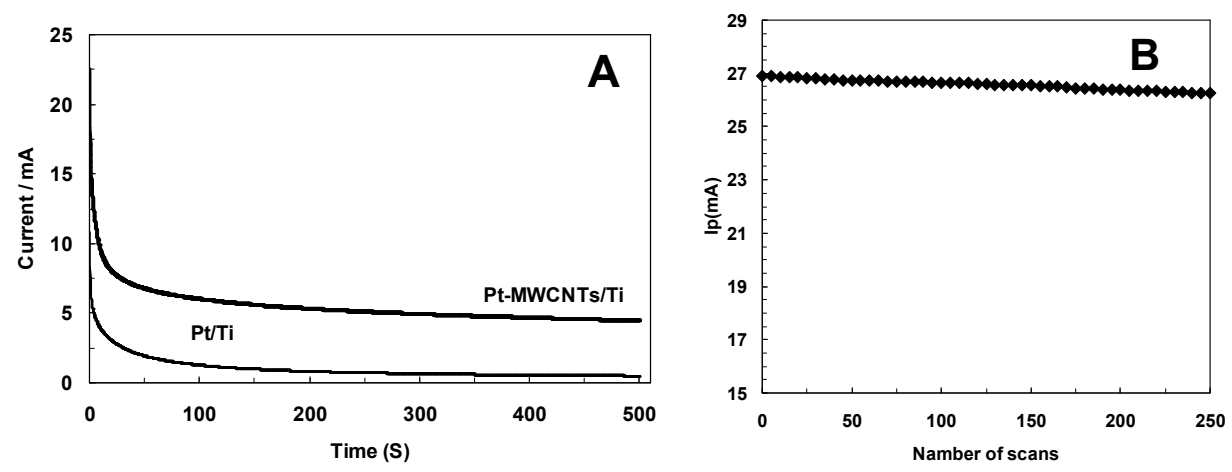

Figure 7. (A) Chronoamperometric curves of methanol oxidation $(0.1 \mathrm{M})$ on the PtMWCNTs/Ti (at $+0.85 \mathrm{~V}$ ) and $\mathrm{Pt} / \mathrm{Ti}$ electrode (at $+0.70 \mathrm{~V}$ ) in $0.1 \mathrm{M} \mathrm{H}_{2} \mathrm{SO}_{4}$ solution. (B) Plot of the main anodic peak currents in the electro-oxidation of Pt-MWCNTs/Ti as a function of the scan number in the cyclic voltammetric method at a scan rate of 100 $\mathrm{mV} \mathrm{s}^{-1}$.

\section{Conclusions}

Pt-MWCNTs/Ti electrodes were prepared by co-deposition of a platinum nanoparticle-MWCNTs composite film on titanium substrates. The morphology and electro-catalytic performance of the electrode was investigated by scanning electron microscopy and cyclic voltammetry, respectively. The results indicated that platinum nanoparticle-multi walled carbon nanotubes were deposited on the surface of titanium. Electrochemical characterization of the Pt-MWCNTs/Ti electrode towards methanol oxidation shows that it has good electro-catalytic activity. The prepared electro-catalyst exhibits satisfactory stability in methanol oxidation. Compared to modified carbon electrodes requiring tedious preparations and pretreatment procedures, Pt-MWCNTs/Ti electrodes can easily be prepared without any further need for modification.

\section{Acknowledgments}

The authors would like to acknowledge the financial support of the Iranian Nanotechnology Society and Isfahan University of Technology (IUT) Research Council. 


\section{References}

1. Rousseau S, Coutanceau C, Lamy C, et al. J Power Sources. 2006;158:1824.

2. Andreadis G, Song SQ, Tsiakaras P. J Power Sources. 2006;157:657-665.

3. Wang ZB, Yin GP, Zhang J, et al. J Power Sources. 2006;160:37-43.

4. He X, Hu C, Liu H. Catal Commun. 2010;12:100-104.

5. Raoof JB, Ojani R, Hosseini SR. Int J Hydrogen Energy. 2011;36:52-63.

6. Steele BCH, Heinzel A. Nature. 2001;414:345-352.

7. Liu YG, Wang YG, Zhang JY, et al. Catal Commun. 2009;10:1244-1247.

8. Zhang XY, Dong DH, Li D, et al. Electrochem Commun. 2008;11:190-193.

9. Xu CW, Shen PK. Chem Commun. 2004;2238-2239.

10. Ganesan R, Lee JS. Angew Chem Int Ed. 2005;44:6557-6560.

11. Matsumoto T, Komatsu T, Arai K, et al. Chem Commun. 2004;840-841.

12. Habibi B, Pournaghi-Azar MH. J Solid State Electrochem. 2010;14:599613

13. Mohd Y, Pletcher D. Electrochim. Acta. 2006;52:786-793.

14. Yi Q, Huang W, Zhang J, et al. Catal Commun. 2008;9:2053-2058.

15. Chatzisymeon E, Dimou A, Mantzavinos D, et al. J Hazard Mater. 2009; 167:268-274.

16. Hosseini MG, Momeni MM. Mol Catal A: Chem. 2012;355:216-222.

17. Wu KB, Fei JJ, Hu SS. Anal Biochem. 2003;318:100-106.

18. Kim KS, Park SJ. Anal Chim Acta. 2013;788:17-23.

19. Pajootan E, Arami M. Electrochim Acta. 2013;112:505-514.

20. Hosseini MG, Momeni MM. Electrochim Acta. 2012;70:1-9.

21. Fujiwara N, Friedrich KA, Stimming U. J Electroanal Chem. 1999;472:120125.

22. Li WS, Tian LP, Huang QM, et al. J Power Sources. 2002;104:281-288.

23. Habibi B, Delnavaz N. Int J Hydrogen Energy. 35 (2010) 8831-8840.

24. Manohara R, Goodenough JB. J Mater Chem. 1992;2:875-887.

25. Razmi H, Habibi Es, Heidari H. Electrochim Acta. 2008;53:8178-8185.

26. Léger J-M, Rousseau S, Coutanceau C, et al. Electrochim Acta. 2005;50:5118-5125.

27. Vigier F, Gloaguen F, Léger JM, et al. Electrochim Acta. 2001;46:43314337.

28. Niu L, Li Q, Wei F, et al. J Electroanal Chem. 2005;578:331.

29. Razmi H, Habibi E. J Solid State Electrochem. 2009;13:1897-1904

30. Bard AJ, Faulkner LR. Electrochemical Methods Fundamentals and Applications. 2nd ed. New York: Wiley; 2004.

31. Golikand AN, Maragheh MG, Sherehjini SS, et al. Electroanalysis. 2006;9:911-918.

32. Angerstein-Kozlowska H, Conway BE, Sharp WBA. J Electroanal Chem. 1973;43:9-16.

33. Conway IS, Marincic N, Gilroy D, et al. J Electrochem Soc. 1966;113:1144-1158.

34. Habibi B, Dadashpour E. Int J Hydrogen Energy. 2013;38:5425-5434. 